cosmic ray research, and was a valuable and comprehensive contribution. The second general review was by $\mathbf{K}$. Wirtz. The author was a member of a research team engaged on the German uranium project, and in his paper he surveyed the limited achievements of the Germans in this direction. The third general paper was delivered by E. Meyer, who surveyed recent developments in acoustics in a comprehensive manner.

In addition to the formal papers read, some specially arranged symposia were held, the visitors from Britain taking part respectively in those on metallic conduction and interferometry. The social programme was indifferent, which was inevitable in view of the difficult conditions in Germany to-day. In view of these quite serious difficulties, the conference must undoubtedly be considered as quite an administrative achievement and augurs well for the future of physical research in Germany, despite the very serious shortage in the current materials of research.

S. 'Tolansky

\section{Statistical Methods}

$\mathrm{T}$ HE first meeting of mathematical statisticians ever held in Germany took place on September $3-4,1947$, in Göttingen. It was attended by British statisticians who had been invited in an endeavour to overcome the difficulties which German mathematicians have experienced by having been cut off from foreign literature for a long time. The losses suffered by libraries in Germany and the impossibility of replacing their stocks contribute to the desire of German scientific workers to resume personal relations with British (or other) contemporaries.

The first meeting was opened by Dr. H. Münzner, professor of theoretical statistics in the University of Göttingen. Prof. P. Riebesell (Hamburg) then gave a critical account of the methods of Grosszahlforschung, showing that this version of the statistical analysis of mass production is either trivial or false. $\mathrm{He}$ discussed the rolation of the normal curve to empirical distributions and suggested a test of the significance of two or more observational modes based on the idea of confidence limits (Mutungsbereich). S. Vajda (London) gave a talk on "The Algebraic Basis of the Analysis of Variance Method" in which he derived well-known formulæ for the tests of effects and interactions of any order by the use of orthogonal polynomials, and pointed out how various possible but different definitions of effects were due to different algebraic constructions (see Nature July 5, p. 27.)

In the afternoon, Miss M. P. Geppert (Kerckhoff Institute, Bad Nauheim) proved by examples that in estimating a parameter from a sample none of the three central measures, mode, mean, or median, of the fiducial distribution needs coincide with the maximum likelihood estimate. Prof. O. N. Anderson (late of Sofia, now at the University of Munich) gave an account of the probloms of inverse probability and fiducial limits, stressing the necessity for deriving formulæ pertinent to a model "without replacement"; he also discussed a formula which should take the place of the $t$-distribution in the case of relative frequencies (which are not normally distributed) for small $n$ and $p \neq(1-p)$.

On September 4, H. L. Seal (London) spoke on non-parametric tests and discussed some of them from the point of view of errors of the first and second kind. Prof. H. Münzner (Göttingen) introduced and solved an integro-difference equation which arises in the description of a 'cascade'-process where a particle multiplies $k$-fold, with probabilities dependent on $k$, at times $t$, the "intensity of multiplication" being dependent on $t$. Finally, Dr. E. Sperner (Oberwolfach) gave an account of his method of expanding meteorological functions in terms of eigenfunctions for the purpose of extrapolation.

An animated discussion took place in the afternoon at the Geophysical Institute, where the participants met by courtesy of the director, Prof. J. Bartels, whose notion of "persistence tendency" applied to time series (see J. Amer. Stat. Assoc., June, 1940) gave rise to talks on a great variety of subjects, ranging from weather forecasts to the Heligoland explosion (see Nature, September 13, p. 350), seismic graphs of which were exhibited.

Many representatives of German statistics were, of course, unable to attend the meeting, but there was much interest in its proceedings. It was felt by all that the comparison of results obtained in ignorance of similar work done in other countries may prove stimulating, though at present Germany has scarcely anything to show which could compare with the fundamental progress achieved in Great Britain and the United States in the last twenty-five years or so. To facilitate the exchange of ideas it was decided to start work on an English-German dictionary of statistical terms, and to supplement it with proposals for a universal notation. Suggestions will be weleorned by Prof. H. Münzner (University of Göttingen, Germany, British Zone), or by the British visitors to the meeting.

S. VAJDA

\section{Petroleum Geology}

$\mathrm{F}$ OR the first time in the course of fifteen years, a meeting of those interested in oil geology was held in Hanover during September 9-11, about five hundred geologists and geophysicists being present. The State Secretaries of the administrative province, representatives of the Military Government, and numerous foreign guests were welcomed by Prof. Bentz, director of the Oil Department of the Reichsamt für Bodenforschung.

During the last fifteen years, several thousand wells have been drilled in north-western Germany, which have considerably increased the theoretical and practical information about the deep subsurface. The main part of the meeting consisted of reports from twenty-six German oil-fields. Their exploration by means of the most up-to-date methods has not only increased the production of the oil industry considerably but also provided much geological and geophysical material, which has helped to clarify the complicated tectonic, stratigraphic and facial conditions of the north-west German Saxonicum. Of the numerous Mesozoic rocks with oil-bearing possibilities from which the production of the north-west German oil-fields is derived, preference is still given to the Zechstein as the source rock of the oil ; this hypothesis, however, was by no means placed in the foreground as the only one. The German oil industry owes its successes to this positive scientific attitude. It is only necessary to mention here the importance of the Ems district for German economic life. With regard to its reserves, this district is among the most important German oil provinces and is thus also an important political factor. 
Twenty oil-fields of north-western Germany are associated with salt domes, fifteen being of the flank type and five of the crestal type. Six fields are located on anticlines ; for example, those of the Ems district. The source rocks are the main dolomite and the porous shale of the Middle Zechstein, the coral oolite of the Malm, the shell banks of the Wealden, the debris layers of the Neocomian, the chalk of the Upper Cretaceous, the sandstones of the Rhætic, the Lower Liassic, the Lower Dogger, Cornbrash, Valendis, and Lower Eocene. Almost all the fields are poor in gas content and subject to edge water drive. In 1946 the total production amounted to about $4,380,000$ barrels.

In April 1947, geophysical results of a general interest were obtained from the blowing-up of the fortifications of the island of Heligoland (see Nature, September 13, p. 350). The depths of the North German area of sedimentation were established as approximately $3 \cdot 1-6 \cdot 2$ miles, while the top of the sima near Göttingen was encountered at a depth of
17 miles, and at 25 miles at the edge of the Alps. The thickness of the continent, hitherto assumed as 37-62 miles, was thus considerably reduced; while fundamentally new knowledge of the major tectonic movements of the earth's crust was obtained.

Thirty-seven reports on the tectonics and palæography of Saxony, geophysical and petrographic methods of investigation, production engineering, and micro-palæontology afforded a comprehensive view of the state of German oil geology.

Many geologists were greatly stimulated by the meeting, and the synthesis between scientific research and its practical application was repeatedly emphasized. This synthesis alone has helped to achieve the results described during the meeting. A full report will be published in due course in the Zeitschrift der Deutschen Geologischen Gesellschaft.

An outcome of the meeting was the decision to found a Deutsche Gesellschaft für Mineralölwissenschaft and a Deutsche Geologische Gesellschaft for the British Zone.

W. RÜHL

\section{THERMIONIC EMISSION FROM OXIDE-COATED CATHODES}

$\mathrm{O}^{\mathrm{x}}$ XIDE-COATED cathodes have been used by the million for many years, but the explanation of the exact mechanism of the thermionic emission from them still presents many interesting physical prob. lems. The summer meeting in London on June 14, arranged by the Electronics Group of the Institute of Physics, on recent work on such cathodes was most opportune, since the war-time use of the cathodes under pulse conditions, and the influence of recent theories of the properties of barrier-layer rectifiers and semiconductors, have stimulated further experimental and theoretical work, and are leading to a revision of views previously held.

Dr. F. A. Vick, of the University of Manchester, began the opening paper by summarizing the position in 1939. Activated cathodes were believed to consist of a mixture of barium and strontium oxides on a metal (normally a nickel alloy) core. Near the surface, strontium oxide was thought to predominate, and adsorbed on the surface a layer of barium, of concentration depending on the equilibrium between diffusion towards the surface and electrolytic movement towards the core during current flow. The high efficiency of oxide cathodes was supposed to be due to the lowering of the effective surface potential barrier by the adsorbed barium $1,2,3,4$, analogous to the action of electro-positive layers on tungsten. Earlier workers had suggested ${ }^{5,8}$ that the observed electron emission is determined by the potential barrier at the core-oxide interface, but by 1939 the role of the core had been relegated to assisting in the dissociation of oxides to provide some free barium.

The war-time use of oxide cathodes in valves used for pulse work directed attention to the fact that the peak saturated current in microsecond pulses could be many times (for example, 100) the normal saturated current at the same nominal temperature. Sproull ${ }^{7}$ described careful experiments on the current-decay characteristics of the cathodes, with anode voltages kept constant for times varying between 100 and 2,000 microsec. and then switched off for times long enough for the cathode to recover. The saturation current rose to an initial high value and then decayed to an asymptote one-fifth to one-fifteenth of the initial value. Sproull suggested that as soon as the thermionic current starts to flow through the oxide, the concentration of the adsorbed barium layer commences to decrease from the equilibrium value under zero current to a new value depending on electrolytic movement through the oxide, and leading to a higher effective work function. Sproull inferred that electrolytic movement is easy through the oxide crystals but difficult across the crystal boundaries. Dr. Vick expressed the view that Sproull's theory is not the whole explanation of pulse effects, though some electrolytic movement of barium may be a contributory factor.

More recently, E. A. Coomes has published ${ }^{8}$ an account of his work on the pulsed properties of oxide cathodes. He produced evidence to show that (i) a cathode giving good results under D.c. conditions is not necessarily a good pulse cathode, (ii) there may be a large temperature rise when heavy currents are drawn, (iii) a major limitation on the maximum pulse current is the onset of 'sparking' or 'flashing', (iv) the effect of the composition of the core metal on pulse properties may be considerable, pure nickel probably being the best. Coomes suggests a different reason for the enhanced emission, namely, that the electrons thermally excited into the conduction band of the oxide semi-conductor during the period between pulses are swept out during the pulse and added to the normal emission for a short period.

Dr. Vick went on to discuss work by Eisenstein and his colleagues on the use of X-rays to study the structure of oxide cathodes ${ }^{2,10}$. The results show, inter alia, that the crystal size of the oxide depends mainly on the maximum temperature reached during activation, that during life the composition of the surface layers becomes nearly pure strontium oxide (confirming previous results), and that special interface compounds are often formed at the core-oxide boundary, associated with an interface resistance vs. current characteristic similar to that exhibited by barrier-layer rectifiers. These and other considerations have led some workers to picture an oxide cathode as made up of the following sections : $(a)$ metal core, $(b)$ rectifying barrier layer, with direction of easy flow towards the core, $(c)$ an excess semiconductor with dispersed interstitial barium, $(d)$ a 